\title{
Organic/Inorganic hybrid stretchable piezoelectric nanogenerators for self-powered wearable electronics
}

\author{
Abhishek. S. Dahiya ${ }^{a}$, Francois Morini $^{a}$, Sarah Boubenia ${ }^{a}$, Kevin Nadaud $^{a}$, Daniel Alquier $^{a}$, \\ Guylaine Poulin-Vittrant ${ }^{b}$
}

${ }^{a}$ GREMAN UMR 7347, Université de Tours, CNRS, INSA-CVL, 16 rue Pierre et Marie Curie, 37071 TOURS Cedex 2, France.

${ }^{\mathrm{b}}$ GREMAN UMR 7347, CNRS, INSA-CVL, Université de Tours, 3 rue de la Chocolaterie, CS 23410, 41034 BLOIS Cedex, France.

*Corresponding author email: abhishek.dahiya@univ-tours.fr

Keywords: zinc oxide, nanowires, piezoelectric, nanogenerator, wearable electronics

\begin{abstract}
Piezoelectric nanocomposites based nanogenerators (NGs) are gaining extensive attention as energy harvesters and self-powered tactile sensors for their applications in wearable electronics and personal healthcare. Herein, we report a facile, cost-effective and industrially scalable process flow for the fabrication of high performance mechanically robust nanocomposites based stretchable nanogenerator (SNG) on polydimethylsiloxane substrate. The inorganic / organic nanocomposite piezoelectric energy harvesting devices are realized by encapsulating the $\mathrm{ZnO}$ nanowires in a parylene $\mathrm{C}$ polymer matrix. The suggested fabrication process flow is implemented to fabricate SNG on flexible bank cards. The SNG devices exhibits excellent performances with a high open circuit voltage $\sim 10 \mathrm{~V}$, short-circuit current density $\sim 0.11 \mu \mathrm{A} / \mathrm{cm}^{2}$, and peak power $\sim 3 \mu \mathrm{W}$ under a vertical compressive force using a mechanical shaker. The obtained electricity from the SNG devices is used to drive electronic devices such as liquid crystal displays without employing any storage unit, implying the device significance in the field of consumer electronics. Besides, commercially available energy harvesting modules is used to store the generated electrical energy in capacitors. Furthermore, the SNG device can be adopted as self-powered wearable tactile sensor for detecting slight body movements which shows its potential applications in autonomous wearable electronics.
\end{abstract}

\section{Introduction}

The thriving interest in flexible, bendable and stretchable electronics has paved the path for the development of new technologies such as light emitting diodes for flexible displays, ${ }^{[1]}$ wearable/biomedical devices, ${ }^{[2]}$ human-machine interface, ${ }^{[3,4]}$ personal healthcare, ${ }^{[5-7]}$ and electronic-skin (e-skin). ${ }^{[8-10]}$ The astonishing progresses in the above-mentioned technologies have made the vision of realizing a new technological drive called 'Internet of things (IoT)' possible, linking billions of different devices/sensors around the world. A successful deployment of IoT may need a widelydistributed sensor network comprising billions or even trillions of sensors which can work autonomously, raising the problem of their energy supply. Noting the limitations of batteries, such as large size, weight, non-flexibility, and finite reservoir of available charges, it would appear that harnessing electrical energy from the ambient means can be the solution to power different devices/sensors to accomplish the IoT vision. While the long-distance data transmission, for example, from mobile devices to home 
computers, can typically be performed only by using the batteries as a power source, the wearable sensing devices with a short-distance wireless link can be powered autonomously. ${ }^{[11]}$

Energy harvesting systems that can be realized on highly flexible, stretchable and foldable substrates, and further the possibility to transfer them on any surface topology could be used for the development of stretchable autonomous electronic devices that find application in IoT, e-skin, biomedical devices such as pacemakers and wearable communication devices. ${ }^{[1,2,8,9]}$ Among various available renewable energy sources in the ambient, kinetic/mechanical energy is ubiquitous and can be a potential source of green energy to power electronic devices. ${ }^{[12]}$ Harvesting mechanical/kinetic energy from body movements to power wearable electronics devices has gained interest in the recent past. ${ }^{[13]}$ In this view, a new field of research on mechanical energy harvesters, so called 'nanogenerators (NGs)', which exploit ambient vibrations as energy source to power the micro/nano systems (MNSs), ${ }^{[14]}$ was proposed for the development of selfpowered electronics. ${ }^{[15]}$ Since the first demonstration of the piezoelectric nanogenerators (PENGs) in the scientific domain in 2006, ${ }^{[16]}$ PENG have been developed and evolved in a variety of configurations. ${ }^{[17]}$ Flexible PENG device structures, such as vertically integrated NG (VING), ${ }^{[18,19]}$ laterally integrated NG (LING), ${ }^{[20]}$ and/or nanocomposite generators $(\mathrm{NCG})^{[21]}$ have been demonstrated using diverse piezoelectric nanomaterials. However, investigations are still needed for the realization of a fully flexible, bendable and stretchable PENG device with high performances able to drive commercial electronics.

Among different PENG device prototypes, VINGs are by far one of the most developed and investigated structure where the vertically grown nanowires (NWs) are encapsulated with a polymer, thus forming a hybrid organic/inorganic composite system. ${ }^{[22-26]}$ Using such a device prototype, Zhu et al. reached to a new milestone in the performance of PENGs devices, demonstrating peak open-circuit voltage and shortcircuit current to a record high level of $58 \mathrm{~V}$ and $134 \mu \mathrm{A}$, respectively, with a maximum power density of $0.78 \mathrm{~W} / \mathrm{cm}^{3}{ }^{[25]}$ Although VING devices showed promising energy harvesting performances, some of the key issues restricting the device performance are yet to be addressed, such as figure of merit (FoM) evaluation, screening effect mitigation, feasibility of technology transfer to fully stretchable system and efficient transfer of mechanical and electrical energy to and from NWs, respectively.

Recently, adopting a comparatively new device prototype, called nanocomposite generators (NCG), researchers are trying to improve the stretchability of the PENG devices. ${ }^{[21,27-34]}$ Conventionally, the NCGs are composed of piezoelectric nanomaterial dispersed in an elastomeric matrix which can also be treated as device substrate. The main advantages of NCG fabrication process are its mechanical robustness, cost effectiveness and the ability to expand it easily to large-scale substrates. The NCG device prototypes were demonstrated using various perovskite nanomaterials such as barium titanate $\left(\mathrm{BaTiO}_{3}\right),{ }^{[21,35]}$ zinc stanate $\left(\mathrm{ZnSnO}_{3}\right)^{[31]}$ and sodium potassium niobate $\left(\left(\mathrm{Na}_{0.5} \mathrm{~K}_{0.5}\right) \mathrm{NbO}_{3}\right) .{ }^{[30]}$ For instance, a hyper stretchable NCG was demonstrated using lead magnesio niobate-lead titanate (PMN-PT) particles in an ecoflex silicone rubber matrix with very long silver NWs as electrode material. ${ }^{[29]}$ The obtained NCG device generated outstanding performance (4V and $500 \mathrm{nA})$ and extraordinary strechability of more than $200 \%$. However, most of the reported NCGs are assembled using perovskite nanostructures that needed high growth temperature (around $1000{ }^{\circ} \mathrm{C}$ ), extra poling step to align their dipoles in one direction, and conductive additives such as carbon nanotubes which adds cost and complexity in the device process. 
In this work, we exploit the advantages of both VING and NCG device prototypes and developed a facile, cost-effective and industrially scalable process flow for the fabrication of high performance, mechanically robust, stretchable nanogenerator (SNG) on polydimethylsiloxane (PDMS) substrate. The active piezoelectric nanomaterial, vertically aligned zinc oxide nanowires ( $\mathrm{ZnO} \mathrm{NWs}$ ), is directly grown on PDMS using low temperature hydrothermal growth process. An inorganic / organic composite type piezoelectric energy harvesting device is realized by encapsulating the $\mathrm{ZnO} \mathrm{NWs}$ in a parylene $\mathrm{C}$ polymer matrix. The decision of adopting parylene $\mathrm{C}$ as the organic matrix has been made while considering its effectiveness of infiltration between the $\mathrm{ZnO}$ NWs, conformity and thickness controllability, and compatibility of this coating technique with flexible substrates. The optimized fabrication process flow is implemented to fabricate SNG on flexible bank cards for potential applications in consumer electronics. The fabricated SNG device prototype is characterized under a periodic compressive force at various frequencies on a wide range of resistive loads (0.1-128 M $\Omega$ ). Under these mechanical excitation conditions, high open circuit voltage and a short circuit current density, as well as a high peak power density on an optimized resistive load, will be demonstrated. The energy generated from the SNG devices can drive liquid crystal displays (LCDs) instantaneously without any storage unit. Besides, commercially available energy harvesting modules will be used to store the generated electrical energy in capacitors. Lastly, we show that the fabricated SNG devices are highly touch sensitive and can be used as self-powered tactile sensors for detecting human motions.

\section{Results and discussions}

Figure 1 illustrates the schematic diagram of the SNG device fabrication process and the final device structure. A thin PMMA layer $(\sim 100 \mathrm{~nm})$ is first spin-coated over a rigid silicon substrate used as a sacrificial layer (Step i). As a flexible and stretchable substrate, PDMS mixture is prepared and spin coated on a rigid substrate. The mass ratio between the PDMS monomer and curing agent is adjusted to 10:1. Then, this mixture is thoroughly mixed and degassed for 1 hour in a desiccator. Following this step, a $\sim 250 \mu \mathrm{m}$ thick PDMS layer, as a stretchable device substrate, is spin-coated $(250 \mathrm{rpm}, 100 \mathrm{rpm} / \mathrm{sec}$, and $15 \mathrm{sec})$ (step ii). The device is then cured overnight at $100{ }^{\circ} \mathrm{C}$ in a convection oven, ensuring appropriate crosslinking of PDMS. Subsequently, in step iii, the bottom electrode (Ti $(100 \mathrm{~nm}) / \mathrm{Pt}(20 \mathrm{~nm})$ or $\mathrm{Ti}(100 \mathrm{~nm}) / \mathrm{Au}(20 \mathrm{~nm}))$ and $\mathrm{ZnO}$ thin film $(50 \mathrm{~nm})$ are sputtered over the cured PDMS. Because of the low lattice mismatch with the Pt (111) and/or Au (111) with $\mathrm{ZnO}$ (0001), ZnO thin film develops a (0001)-oriented wurtzite crystalline structure (supporting information Figure S1). ${ }^{[36,37]}$ A low temperature hydrothermal process is used for the growth of vertically aligned $\mathrm{ZnO}$ NWs (step iv). The growth recipe is described in our previously reported work. ${ }^{[38]}$ The presence of (0001)-oriented $\mathrm{ZnO}$ thin film forces the $\mathrm{ZnO} \mathrm{NWs}$ to grown in caxis due to their epitaxial relationship. Following, the as-grown $\mathrm{ZnO} \mathrm{NWs}$ on PDMS are transferred into a chemical vapor deposition (CVD) system for the deposition of parylene $\mathrm{C}$ film ( $\sim 600 \mathrm{~nm}$ ) (step v). The active area of the device is defined by depositing top metal of $\sim 100 / 400 \mathrm{~nm} \mathrm{Ti} / \mathrm{Al}$ layers using a shadow mask (step vi). Finally, the copper wires are connected to top and bottom electrodes using epoxy silver paste and the whole device is packaged in PDMS to improve the robustness of the SNG device and to prevent any moisture and/or dust particle to stick onto the top metal. At the end, the complete device is lifted-off from the rigid silicon substrate making it highly foldable, flexible and stretchable (step vii).

The morphological and structural characterization of the piezoelectric $\mathrm{ZnO}$ NWs and $\mathrm{ZnO}$ $\mathrm{NW}$-parylene $\mathrm{C}$ is carried out using scanning emission microscopy (SEM) and X-ray diffraction (XRD) and the corresponding results are shown in Figure 2. Figure 2a shows both 
low and high magnification SEM images of the as-grown ZnO NWs on PDMS. It can be seen from Figure 2a that the NWs are vertically aligned over the entire PDMS surface. From the assessment of several SEM images, $\mathrm{ZnO} \mathrm{NW}$ density, diameter and length are obtained to be $\sim 100 \mathrm{NW} \mu \mathrm{m}^{-2}, 50 \mathrm{~nm} \pm 20 \mathrm{~nm}$ and $0.5 \mu \mathrm{m} \pm 0.1 \mu \mathrm{m}$ respectively, after a 6-hour growth process. From the XRD data (Figure $2 b$ ), we can see a sharp dominant peak centered at $2 \theta$ $34.4^{\circ}$, corresponding to the $(0002)$ planes of a highly c-axis oriented wurtzite $\mathrm{ZnO}$. It is to note that no additional peaks are observed for wurtzite $\mathrm{ZnO}$ in the XRD data, confirming a growth of highly c-axis oriented NWs perpendicular to the PDMS surface. Additional peaks appearing at $38.5^{\circ}$ and $39.8^{\circ}$ are successfully assigned to the bottom electrode made of Ti/Pt. The morphological and structural characterizations hence confirmed the growth of high quality c-axis aligned $\mathrm{ZnO} \mathrm{NWs}$ which is prerequisite for the fabrication of high performance VING devices. ${ }^{[25]}$

The latest VING device prototype, first demonstrated by Zhu et al., ${ }^{[25]}$ offers great potential to further enhance the device performances. In this prototype, along with the quality and orientation of NWs, the polymer matrix is also expected to play a major role in defining the device performance. However, little effort has been dedicated in this area of research. The critical points to consider for a polymer matrix to be efficient are: (i) infiltration between the NWs, (ii) the insulating layer thickness above the NWs and, (iii) conformal deposition of polymer matrix to completely cover all the NWs. Considering the first point, polymer infiltration between NWs is important to suppress the charge screening-effect from neighboring NWs and also to transfer the applied force equally to all NWs. Infiltration of polymer, into $\mathrm{ZnO} \mathrm{NWs}$, depends on many factors such as: (1) density of ZnO NWs and (2) Young's modulus of the polymer. A low density of NWs is the logical choice for good infiltration, however while using low density NW grown substrate, the active piezoelectric material and total capacitance of the system will be reduced. Thus, the expected power density will be low. Therefore, the idea is to have a medium to high density of NWs and to choose a polymer with ideal mechanical and electrical characteristics. Indeed, a low Young's modulus and permittivity is favored for the polymer to infiltrate between NWs, in order to maximize the energy stored in the NG. ${ }^{[39]}$ Considering the second aspect, the insulating layer should be as thin as possible at the top of the NWs to increase the capacitive coupling between top metal and NWs, without losing its insulation role. However, care must be taken so that the generated potential may not break the insulation barrier. At last, conformal deposition of polymers is needed to have same thickness of the polymer all over the surface. It is well known in the literature that with the hydrothermally grown NWs, chunks of NWs can be present over the NWs surface which comes as a result of homogeneous nucleation in the growth solution. In the case of a non-conformal polymer coating, such impurities on top of the surface can connect the top metal to the bottom electrode via ZnO NWs. This results into a very low device resistance which affects the device yield and performances. In this framework, we investigate five different encapsulation polymers, namely: PDMS, Polymethyl methacrylate (PMMA), poly ((3,4-ethylene-dioxythiophene)poly(styrenesulfonate)) (PEDOT: PSS), poly (3,4- ethylenedioxythiophene-Tosylate (PEDOT: ToS) and parylene C. The results of the encapsulation study are summarized in terms of infiltration of polymer, conformity, thickness controllability and compatibility of polymer coating techniques with plastic substrates (Figure S2 and Table S1).

Based on the above mentioned requirements and experimental results shown in Figure S2, parylene $\mathrm{C}$ is chosen as the organic matrix for the fabrication of inorganic/organic hybrid SNG. Figure S3 shows a typical SEM image of the fabricated SNG on PDMS. In literature, most often, PMMA is employed for the fabrication of high performance PENG devices. ${ }^{[23-25]}$ However, the poor conformity exhibited by spin coated PMMA resulted in low device yield in the present work (Figure S2a). For the deposition of parylene $\mathrm{C}$ as insulating layer, a room temperature vapor phase deposition process is chosen in order to ensure that the organic / 
inorganic hybrid PENG devices, investigated in this work, were fully compatible with low temperature device assembly protocols. However, to better observe the infiltration capability and conformal coverage of parylene $\mathrm{C}$ over $\mathrm{ZnO} \mathrm{NWs}$, they are grown on silicon substrate with low NW density and similar device fabrication process was carried out as for SNG devices. A typical SEM image of the resulting NWs on silicon is shown in Figure 2c. Following, the sample was transferred into a CVD system for the parylene C deposition. Figure $2 \mathrm{~d}$ shows the SEM image after parylene $\mathrm{C}$ and metal deposition. It can be seen from this image (Figure 2d) that NWs are completely encapsulated by parylene $\mathrm{C}$ film. The deposition process is very conformal with high degree of infiltration between the NWs. A schematic illustrating the NCG device structure is shown in Figure 2e.

The functional characterizations of the SNG devices are done after removing the final synthesized device from the rigid substrates (in case they are processed on rigid substrates). The fabricated inorganic ( $\mathrm{ZnO} \mathrm{NWs)} \mathrm{/} \mathrm{organic} \mathrm{(parylene} \mathrm{C)} \mathrm{hybrid} \mathrm{SNGs} \mathrm{are} \mathrm{characterized}$ using a custom built test bench in order to assess their energy harvesting performance and the results are shown in Figure 3. The test bench set up is shown in Figure S4. Typical optical micrographs of freely suspended SNG devices on PDMS substrate are shown in Figure 3a. The exceptional device flexibility is tested by folding and stretching the device as shown in Figure 3a panel ii and iii. Next, the fabricated SNG devices are carefully functionally characterized using the current experimental setup. First, the energy harvesting performances of SNG devices are measured under different amplitudes of compressive pressure $(50-110 \mathrm{kPa})$. It is well know that for PENG devices, the voltage generation is directly proportional to the applied stress. Therefore, it is expected that output voltage will be pressure sensitive. ${ }^{[40]}$ As seen from the Figure $3 b$, the open circuit voltage ( $\mathrm{V}_{\mathrm{OC}}$ ) amplitude increases from 3 to $9.1 \mathrm{~V}$ with the increase of compressive pressure amplitude from 50 to $110 \mathrm{kPa}$, respectively measured across $128 \mathrm{M} \Omega$ resistive load. The peak output voltage values are plotted at corresponding applied pressure to calculate the sensitivity of the present device (Figure 3c). The sensitivity (S) is calculated taking the slope of the linear fitting curve of the experimental data shown in Figure $3 c$. The obtained sensitivity value $\left(S=0.09 \mathrm{~V} \cdot \mathrm{kPa}^{-1}\right)$ is higher than previously reported triboelectric NG based pressure sensors. ${ }^{[41,42]}$ Furthermore, the output power and voltage are measured with different operating frequency. Energy harvesting devices generally present internal impedance to the load circuits and in general, the maximum output power $\left(P_{\max }\right)$ is obtained when the load impedance is matched to that of the harvester. Therefore, the optimal power transfer conditions for various operating frequencies are assessed by measuring the output power across wide range of resistive loads $\left(\mathrm{R}_{\mathrm{L}}\right)$, given by:

$$
P_{\max }=\left(V_{R L} \times I_{R L}\right)_{\max }
$$

where $V_{R L}$ and $I_{R L}$ is the instantaneous peak voltage and current at a given resistive load, respectively. Figure $3 \mathrm{~d}$ shows a plot of the peak output power against wide range of resistive load for various operating frequencies. The low frequency range $(3-7 \mathrm{~Hz})$ is chosen for the present experiments as it is the typical vibrational frequency range present in our day-to-day life environment (walking, machine vibrations, etc.). The optimal load resistance for the maximum power transfer for various frequencies is found in between 10-20 M $\Omega$. The maximum output power, using Equation 1, achieved from a SNG device is approximately $580 \mathrm{nW}$ at an operating frequency of $7 \mathrm{~Hz}$ and compressive pressure of $50 \mathrm{kPa}$. Further, Figure $3 \mathrm{e}$ shows the waveform of output voltages for different frequencies across $30 \mathrm{M} \Omega$ resistance under similar excitation conditions. As can be seen from Figure $3 d$ and e, the magnitude of output power and voltage, respectively increased with operational frequency. This is expected because 
the current generated from the piezoelectric material is proportional to the rate of strain. ${ }^{[43]}$

It is indeed important to compare the obtained SNG device performances with the state-of-the-art values for $\mathrm{ZnO}$ based PENG devices. Table 1 cites some of the interesting reports available in the literature. As can be seen from Table 1, the values reported by Zhu et al. are still the best in the literature. However, it is to note that the applied stress value $(1 \mathrm{MPa})$ is 10 times higher compared to the present work. ${ }^{[25]}$ Furthermore, the present proposed SNG device process is on fully flexible and stretchable platform compared to theirs on rigid silicon substrate. This set of observations shows the importance of the present proposed process for high performance PENG devices.

A switch polarity test is carried out on SNG and reference devices (without NWs) using opposite connections to demonstrate the reversibility of the obtained voltage peaks, in order to prove that the output voltages are due to piezoelectric phenomenon. ${ }^{[4]}$ A complete reversal of an output voltage signal is observed when reversing the connections (Supporting information Figure S5). It is worth to mention that the observed output signal may arise because of piezoelectric properties of parylene $\mathrm{C}$ polymer. ${ }^{[45]}$ However, its piezoelectric coefficient $\left(\mathrm{d}_{33} \sim\right.$ $0.2 \mathrm{pm} / \mathrm{V})$ is 60 times lower than bulk $\mathrm{ZnO}\left(\mathrm{d}_{33} \sim 12 \mathrm{pm} / \mathrm{V}\right)$ and further, poling step is needed to have any piezoelectric response from it. ${ }^{[4]}$ It is to note that we have not applied any voltage bias to the SNG devices before or during the measurements. Therefore, we can rule out any contribution from the parylene $\mathrm{C}$ to the observed piezoelectric response from our SNG device. Nonetheless, to avoid any discrepancy, we have also characterized reference devices, fabricated without incorporating $\mathrm{ZnO}$ NWs, under similar loading conditions. The results are shown in Figure S5b. It can be seen from this Figure, the SNG devices gave 70 times higher peak-to-peak voltages compared to reference devices. The obtained signals from the reference devices are also completely reversible. The origin of such small voltage output from the reference devices can be related to either flexoelectric effects from polymers ${ }^{[46]}$ and/or change of PDMS capacitance. ${ }^{[9]}$ Nevertheless, it can be concluded from these characterization results that the major contribution for the observed output voltage signals from SNG devices is due to piezoelectric phenomenon.

The alternating-current (AC) type charge generation mechanism exhibited by the SNG devices is explained with the help of schematics shown on Figure 4. The piezoelectric charge induced electron flow mechanism, for VING devices, is well documented in the literature. ${ }^{[16,22,24-26,28]}$ In case of no excitation (Figure 4a), there is no electric field to drive the electrons in the outer circuit and thus, we observe no voltage generation across the resistive load. When a vertical compressive force is applied over the top of the SNG device (Figure $4 \mathrm{~b}$ ), piezopotential difference, between the top and bottom electrodes, is developed. The essence of the potential generated is the relative displacement of the centers of the cations and anions in the $\mathrm{ZnO}$ NWs, resulting in a microscale dipole moment. Polarization from all of the units, inside $\mathrm{ZnO} \mathrm{NWs}$, results in a macroscopic potential drop, called "piezopotential", along the straining direction in the single crystalline NWs. The crystallographic orientation of NW's c-axis will determine the type of charges generated at the top and bottom electrodes. For a $\mathrm{ZnO}$ NWs, all aligned along the positive c-axis, negative charges are generated at the top while positive charges at the bottom electrode, in presence of a compressive strain. The polarization induced electric field (E) drives the flow of electrons in the external circuit, as shown in Figure 4b. Further, when the vertical compressive force is removed (Figure 4c), the piezoelectric effect is abated due to the slow relaxation of the PDMS substrate. Consequently, the electric field direction is reversed and the electrons flow back in the reverse direction (from bottom to top) and an electric signal is detected in opposite direction. This explains the AC type voltage and current output from our SNG devices during periodic compressive stress.

The proposed fabrication process for the SNG devices is substrate independent. The proofof-device concept and its scalability are demonstrated by fabricating SNG on typical bank 
cards $(5 \times 3 \mathrm{~cm})$. The optical image of the fabricated device and its functional characterization results are shown in Figure 5. The integration of SNGs in the back plane of a flexible bank cards can be seen from the optical micrograph shown in Figure 5a. In the Figure 5a, the three rectangular shaped top electrodes are connected in parallel configuration to enhance the output current across the load resistance. The applied force on the $\mathrm{SNG}$ device is $13 \mathrm{~N}$ at $5 \mathrm{~Hz}$ and the total compressive area is $8 \mathrm{~cm}^{2}$. The SEM picture shows the as-grown $\mathrm{ZnO} N W \mathrm{~s}$ on bank cards. From this Figure we can see highly aligned uniform growth of $\mathrm{ZnO} N W$ s. Figure $5 \mathrm{~b}$ and $\mathrm{c}$ shows a plot of electrical output characteristics and peak output power, respectively against wide range of resistive loads. A typical bell-shaped output power curve as a function of resistive load is obtained (Figure 5c). It can be seen from Figure 5b, as the load resistance increases over $1 \mathrm{M} \Omega$, the voltage amplitude starts to rise while the current amplitude drops. Correspondingly, the peak output power, reaches a maximum value of $3 \mu \mathrm{W}$ at an optimal load of $10 \mathrm{M} \Omega$ (Figure 5c). In general, increasing the number of electrodes or device area can considerably promote the electric output of the NGs. Consequently, the present SNG device on back cards showed enhancement of peak power $(\sim 3 \mu \mathrm{W})$ compared to the SNG device shown in Figure 3 with smaller device area. Being pressed by a human palm, the peak value of open circuit voltage and short circuit current exceeded $27 \mathrm{~V}$ and $11 \mu \mathrm{A}$, respectively (Figures $5 \mathrm{~d}$ ), with the peak maximum power of $\sim 35 \mu \mathrm{W}$ at 100 $\mathrm{kPa}$ of compressive pressure.

For the potential utilization of the electric output power generated from the SNG, we first demonstrate the charging of commercial capacitors and then to power consumer electronic devices such as LCDs. To provide the rectified output, commercially available self-powered energy harvesting module (EH300/301 EPAD®) is used to charge $1 \mathrm{mF}$ capacitor (Figure 6a). The entire charging process is recorded by monitoring the voltages across the capacitor. Figure 6a further shows the charging curves of the capacitor recorded under different applied pressure conditions. As it can be seen from this Figure, higher compressive pressure yielded faster charging of the capacitor. At $100 \mathrm{kPa}$, the voltage across $1 \mathrm{mF}$ capacitor can reach to about $100 \mathrm{mV}$ in $900 \mathrm{sec}(15 \mathrm{~min})$. The slow rate of capacitor charging $\left(\sim 0.1 \mathrm{mV} . \mathrm{s}^{-1}\right)$ is reasonable as large amount of current will be consumed by energy harvesting module, EH300. Nevertheless, the SNG device can be directly connected to power a number of small electronics (Figure 6b). The SNG device is excited using mechanical shaker by applying $13 \mathrm{~N}$ of compressive forces. As shown in Figure $6 \mathrm{~b}$ and Movie S1 (Supporting Information), many digits of a LCD screen can be driven without any external circuits using the SNG implying the device significance in the field of consumer electronics.

Wearable electronics is one of the most exciting and emerging technologies that has the potential to revolutionize the human life. The important requirements for wearable devices are: (i) should be highly flexible and stretchable to absorb more strain while body movements, (ii) compact and small size, (iii) high sensitivity, and (iv) biocompatible. Considering the demonstration of tactile sensing capability, a highly sensitive touch sensor with extreme flexibility is needed. ${ }^{[40,47]}$ The high sensitivity $\left(0.09 \mathrm{~V} \cdot \mathrm{kPa}^{-1}\right)$ and flexibility of our SNG devices (Figure 3 ) is sufficient to measure the slight body movements, proving the potential applications for wearable electronic systems such as human-machine interaction, fatigue detection, e-skin, etc. To obtain enhanced body motion sensor responses, we measure the voltage response from SNG, by attaching it to the skin of index finger using a double side carbon scotch. The ability of the sensor device, to detect the cyclic bending and releasing motion of index finger, is monitored and shown in Figure 7. The convex bending induces the strain distribution along the c-axis of $\mathrm{ZnO} \mathrm{NWs}$, resulting in negative piezopotential on the top surface and positive at the bottom as shown in the bottom inset of Figure $7 \mathrm{a}$. The potential 
gradient is sufficient to drive the electrons in the outer circuit which gives $\mathrm{V}_{\mathrm{OC}}$ between 2 and 4V (Figure 7c). On strain removal (Figure 7b), peaks at the negative side are detected due to the reversal of the electric field (inset in Figure 7b). The high sensitivity of the SNG devices can be applied for the advancement of many fields such as personal health care and humanmachine interfaces.

It is important to note that the metal electrodes used in the SNG devices do not possess stretchable features. However, the main idea is to show that the proposed fabrication process can be carried out on flexible and stretchable PDMS substrates with high performances. Stretchable conductors are indeed one of the important components for stretchable electronics. Promising nanomaterials including silver NWs, carbon nanotubes (CNTs), graphene, copper NWs and so on are under research scrutiny for the development of stretchable electronics. ${ }^{[48]}$ However, the stability issues under cyclically applied mechanical stress are still considered to be one of the main hurdles in adopting these nanomaterials as stretchable conductors. Nevertheless, we are trying to develop a fully stretchable and transparent SNG device using stretchable silver NWs metal interconnects.

\section{Conclusion}

In summary, we have demonstrated an industrially scalable process flow for the fabrication of high performance mechanically robust stretchable nanogenerators (SNG) on PDMS substrates. The SNG devices composed of inorganic / organic piezoelectric nanocomposite, was built using $\mathrm{ZnO}$ NWs (inorganic) and parylene $\mathrm{C}$ (organic) matrix. The as-synthesized $\mathrm{ZnO} \mathrm{NWs}$ were highly-crystalline and aligned in c-axis direction perpendicular to the growth substrate. The SNG devices exhibits excellent performance with a high piezoelectric open circuit voltage and output short-circuit current density. The proof-ofdevice concept and its scalability were demonstrated by fabricating SNG on typically available bank cards with peak output power reaching to $35 \mu \mathrm{W}$ under a $100 \mathrm{kPa}$ dynamic vertical compressive pressure. The obtained electricity from the SNG devices was used to drive electronic devices such as liquid crystal displays without employing any storage unit. The fabricated SNG demonstrated to be a highly sensitive tactile sensor by wearing it onto the skin of a human index finger. A gentle strain induced by the bending of the finger generated a peak open circuit voltage of more than $3 \mathrm{~V}$. The results obtained from the fabricated organic / inorganic nanocomposite SNG devices clearly demonstrate the interest of our novel fabrication process for the development of autonomous wearable electronics for personal health care and human-machine interfaces.

\section{Experimental Section}

\subsection{Growth of $\mathrm{ZnO}$ nanowires:}

Hydrothermal growth method was used for the growth of $\mathrm{ZnO}$ NWs. First, $\mathrm{ZnO}$ thin-films were deposited using sputtering technique at room temperature (RT). During the sputtering process, the RF power was fixed at $65 \mathrm{~W}$ while the deposition is carried at $5 \mathrm{mTorr}$ pressure in Ar ambient. For a typical NW growth process, $50 \mathrm{~nm}$ of $\mathrm{ZnO}$ thin film is deposited via sputtering process. Then, for the growth of $\mathrm{ZnO} \mathrm{NWs}$, substrates with the $\mathrm{ZnO}$ seed layer were then immersed face down in a Teflon flask containing a solution of 1:1 molar ratio of $\mathrm{Zn}\left(\mathrm{NO}_{3}\right)_{2}$, and hexamethylenetetramine (HMTA) $(50 \mathrm{mM})$ and PEI $(5 \mathrm{mM})$ is added. The flask was subsequently sealed inside a stainless steel autoclave reactor and placed in a preheated convection oven (Memmert 100 universal) at $\sim 90{ }^{\circ} \mathrm{C}$ for $6 \mathrm{~h}$.

\subsection{Parylene $\mathrm{C}$ deposition:}


A room-temperature (RT) vapor phase deposition process was chosen for the deposition of parylene $\mathrm{C}$ as dielectric layers. A three stage deposition system (sublimation, pyrolysis, and polymerization), which afforded RT polymerization during deposition, was used. The parylene $\mathrm{C}$ films were formed by vaporizing the powdered dimer over $100{ }^{\circ} \mathrm{C}$, creating molecular changes in the gaseous dimer by thermal energy at approximately $690{ }^{\circ} \mathrm{C}$, and polymerization on the chosen substrate at RT.

\subsection{Measurement and characterizations:}

The measurement apparatus is carefully designed to minimize anomalous signals that can occur due to effects other than piezoelectric ones. The experimental test bench is a mechanical shaker equipped with an actuator arm, which is made of carbon fiber for low weight, strength and rigidity. The amplitude and frequency of the shaker are controlled via an Agilent 33 250A function generator and a LDS PA100E power amplifier is used to drive the shaker. The actuator arm is attached to the reciprocating shaker platform at one end and a height adjustable screw is inserted through it at the opposite end. To avoid excessive damage to the SNGs during testing, the screw tip is also insulated by soft styrene-butadiene rubber. The SNGs are then firmly fixed onto a solid aluminium block using double sided adhesive tape. The screw tip is positioned over the active region of the SNG, without making contact.

Acknowledgements

This work was financially supported by Region Centre (France) through the project APRMEPS and by the National Research Agency funding (Grant ANR-14-CE08-0010-01) and by ECSEL JU (Grant agreement $\mathrm{N}^{\circ} 692482$ ). This JU receives support from the European Union's H2020 research and innovation programme and France, Netherlands, Denmark, Belgium, Germany, Czech Republic, Spain.

\section{References}

[1] J. Yoon, S. Y. Hong, Y. Lim, S. J. Lee, G. Zi, J. S. Ha, Adv. Mater. 2014, 26, 6580.

[2] D.-H. Kim, N. Lu, R. Ghaffari, Y.-S. Kim, S. P. Lee, L. Xu, J. Wu, R.-H. Kim, J. Song, Z. Liu, J. Viventi, B. de Graff, B. Elolampi, M. Mansour, M. J. Slepian, S. Hwang, J. D. Moss, S.-M. Won, Y. Huang, B. Litt, J. a. Rogers, Nat. Mater. 2011, 10, 316.

[3] T. Yamada, Y. Hayamizu, Y. Yamamoto, Y. Yomogida, A. Izadi-Najafabadi, D. N. Futaba, K. Hata, Nat Nano 2011, 6, 296.

[4] E. Roh, B. U. Hwang, D. Kim, B. Y. Kim, N. E. Lee, ACS Nano 2015, 9, 6252.

[5] D. Son, J. Lee, S. Qiao, R. Ghaffari, J. Kim, J. E. Lee, C. Song, S. J. Kim, D. J. Lee, S. W. Jun, S. Yang, M. Park, J. Shin, K. Do, M. Lee, K. Kang, C. S. Hwang, N. Lu, T. Hyeon, D.-H. Kim, Nat Nano 2014, 9, 397.

[6] C. L. Choong, M. B. Shim, B. S. Lee, S. Jeon, D. S. Ko, T. H. Kang, J. Bae, S. H. Lee, K. E. Byun, J. Im, Y. J. Jeong, C. E. Park, J. J. Park, U. I. Chung, Adv. Mater. 2014, $26,3451$.

[7] X. Wang, Y. Gu, Z. Xiong, Z. Cui, T. Zhang, Adv. Mater. 2014, 26, 1336.

[8] J. H. Lee, K. Y. Lee, M. K. Gupta, T. Y. Kim, D. Y. Lee, J. Oh, C. Ryu, W. J. Yoo, C. Y. Kang, S. J. Yoon, J. B. Yoo, S. W. Kim, Adv. Mater. 2014, 26, 765.

[9] S. Park, H. Kim, M. Vosgueritchian, S. Cheon, H. Kim, J. H. Koo, T. R. Kim, S. Lee, G. Schwartz, H. Chang, Z. Bao, Adv. Mater. 2014, 26, 7324.

[10] W. H. Yeo, Y. S. Kim, J. Lee, A. Ameen, L. Shi, M. Li, S. Wang, R. Ma, S. H. Jin, Z. Kang, Y. Huang, J. a. Rogers, Adv. Mater. 2013, 25, 2773.

[11] A. Bonfiglio, D. De Rossi, Wearable Monit. Syst. 2011, 1. 
[12] Z. L. Wang, Mater. Today 2017, 00, 1.

[13] C. Dagdeviren, B. D. Yang, Y. Su, P. L. Tran, P. Joe, E. Anderson, J. Xia, V. Doraiswamy, B. Dehdashti, X. Feng, B. Lu, R. Poston, Z. Khalpey, R. Ghaffari, Y. Huang, M. J. Slepian, J. a Rogers, Proc. Natl. Acad. Sci. 2014, 111, 1927.

[14] Z. L. Wang, W. Wu, Angew. Chemie Int. Ed. 2012, 51, 11700.

[15] F. R. Fan, W. Tang, Z. L. Wang, Adv. Mater. 2016, 28, 4283.

[16] Z. L. Wang, J. Song, Science (80-. ). 2006, 312, 242.

[17] F. Hu, Q. Cai, F. Liao, M. Shao, S. T. Lee, Small 2015, 11, 5611.

[18] V. F. Rivera, F. Auras, P. Motto, S. Stassi, G. Canavese, E. Celasco, T. Bein, B. Onida, V. Cauda, Chem. - A Eur. J. 2013, 19, 14665.

[19] X. Wang, J. Song, J. Liu, Z. L. Wang, Science 2007, 316, 102.

[20] S. Xu, Y. Qin, C. Xu, Y. Wei, R. Yang, Z. L. Wang, Nat. Nanotechnol. 2010, 5, 366.

[21] K. Il Park, M. Lee, Y. Liu, S. Moon, G. T. Hwang, G. Zhu, J. E. Kim, S. O. Kim, D. K. Kim, Z. L. Wang, K. J. Lee, Adv. Mater. 2012, 24, 2999.

[22] Z. L. Wang, Adv. Mater. 2012, 24, 280.

[23] Y. Hu, C. Xu, Y. Zhang, L. Lin, R. L. Snyder, Z. L. Wang, Adv. Mater. 2011, 23, 4068.

[24] Y. Hu, Y. Zhang, C. Xu, L. Lin, R. L. Snyder, Z. L. Wang, Nano Lett. 2011, 11, 2572.

[25] G. Zhu, A. C. Wang, Y. Liu, Y. Zhou, Z. L. Wang, Nano Lett. 2012, 12, 3086.

[26] Y. Hu, L. Lin, Y. Zhang, Z. L. Wang, Adv. Mater. 2012, 24, 110.

[27] K. Il Park, C. K. Jeong, J. Ryu, G. T. Hwang, K. J. Lee, Adv. Energy Mater. 2013, 3, 1539.

[28] M. K. Gupta, S. W. Kim, B. Kumar, ACS Appl. Mater. Interfaces 2016, 8, 1766.

[29] C. K. Jeong, J. Lee, S. Han, J. Ryu, G. T. Hwang, D. Y. Park, J. H. Park, S. S. Lee, M. Byun, S. H. Ko, K. J. Lee, Adv. Mater. 2015, 27, 2866.

[30] H. B. Kang, J. Chang, K. Koh, L. Lin, Y. S. Cho, ACS Appl. Mater. Interfaces 2014, 6, 10576.

[31] K. Y. Lee, D. Kim, J. Lee, T. Y. Kim, M. K. Gupta, S. Kim, Adv. Funct. Mater. 2014, $24,37$.

[32] C. K. Jeong, K. Park, J. Ryu, G. Hwang, K. J. Lee, Adv. Funct. Mater. 2014, 24, 2620.

[33] Jeong C. K.; Kim I.; Park K.-I.; Oh M. H.; Paik H.; Hwang G.-T.; No K.; Nam Y. S.; Lee K. J., ACS Nano 2013, 7, 11016.

[34] L. Persano, C. Dagdeviren, C. Maruccio, L. De Lorenzis, D. Pisignano, Adv. Mater. 2014, 26, 7574.

[35] X. Chen, X. Li, J. Shao, N. An, H. Tian, C. Wang, T. Han, L. Wang, B. Lu, Small 2017, 13, 1 .

[36] F. Stavale, L. Pascua, N. Nilius, H. Freund, J. Phys. Chem. C 2013, 117, 10552.

[37] B. H. Liu, J. A. Boscoboinik, Y. Cui, S. Shaikhutdinov, H. J. Freund, J. Phys. Chem. C 2015, 119, 7842 .

[38] C. Opoku, A. S. Dahiya, C. Oshman, C. Daumont, F. Cayrel, G. Poulin-Vittrant, D. Alquier, N. Camara, Nanotechnology 2015, 26, 355704.

[39] R. Tao, G. Ardila, L. Montes, M. Mouis, Nano Energy 2014, 14, 62.

[40] C. Hu, L. Cheng, Z. Wang, Y. Zheng, S. Bai, Y. Qin, Small 2016, 12, 1315.

[41] K. Parida, V. Bhavanasi, V. Kumar, R. Bendi, P. S. Lee, Nano Res. 2017, 1.

[42] Y. Fu, H. He, Y. Liu, Q. Wang, L. Xing, X. Xue, J. Mater. Chem. C 2017, 5, 1231.

[43] D. Yun, J. Park, K.-S. Yun, Electron. Lett. 2015, 51, 284.

[44] S. Xu, Y. Qin, C. Xu, Y. Wei, R. Yang, Z. L. Wang, Nat. Nanotechnol. 2010, 5, 366.

[45] J. Y. Kim, A. Cheng, Y. Tai, 2011 IEEE 24th Int. Conf. Micro Electro Mech. Syst. 2011, 473.

[46] X. Jiang, W. Huang, S. Zhang, Nano Energy 2013, 2, 1079.

[47] X. Pu, M. Liu, X. Chen, J. Sun, C. Du, Y. Zhang, J. Zhai, W. Hu, Z. L. Wang, Sci. Adv. 2017, 3, e1700015. 
[48] T. Q. Trung, N. E. Lee, Adv. Mater. 2017, 29, 1.

[49] R. Tao, M. Parmar, G. Ardila, P. Oliveira, D. Marques, Semicond. Sci. Technol. 2017, 32, 64003.

[50] Y. Hu, L. Lin, Y. Zhang, Z. L. Wang, Adv. Mater. 2012, 24, 110.

[51] K. C. Pradel, W. Wu, Y. Ding, Z. L. Wang, Nano Lett. 2014, 14, 6897.

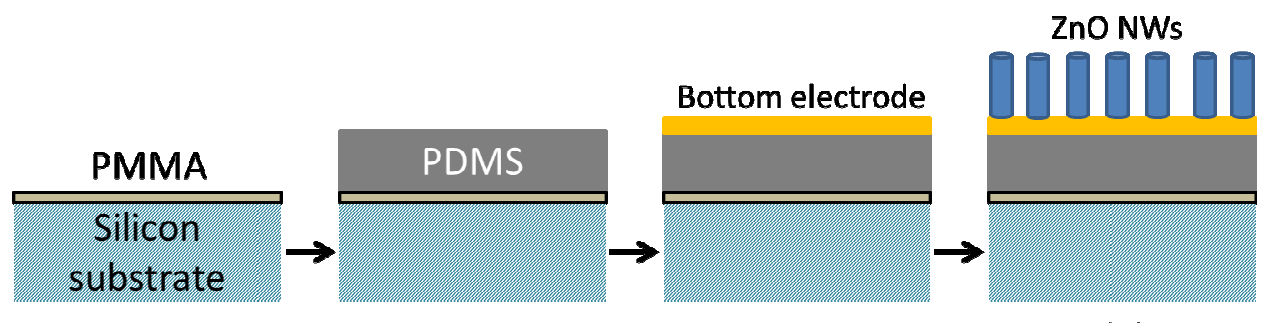

(i)

(ii)

(iii)

(iv)

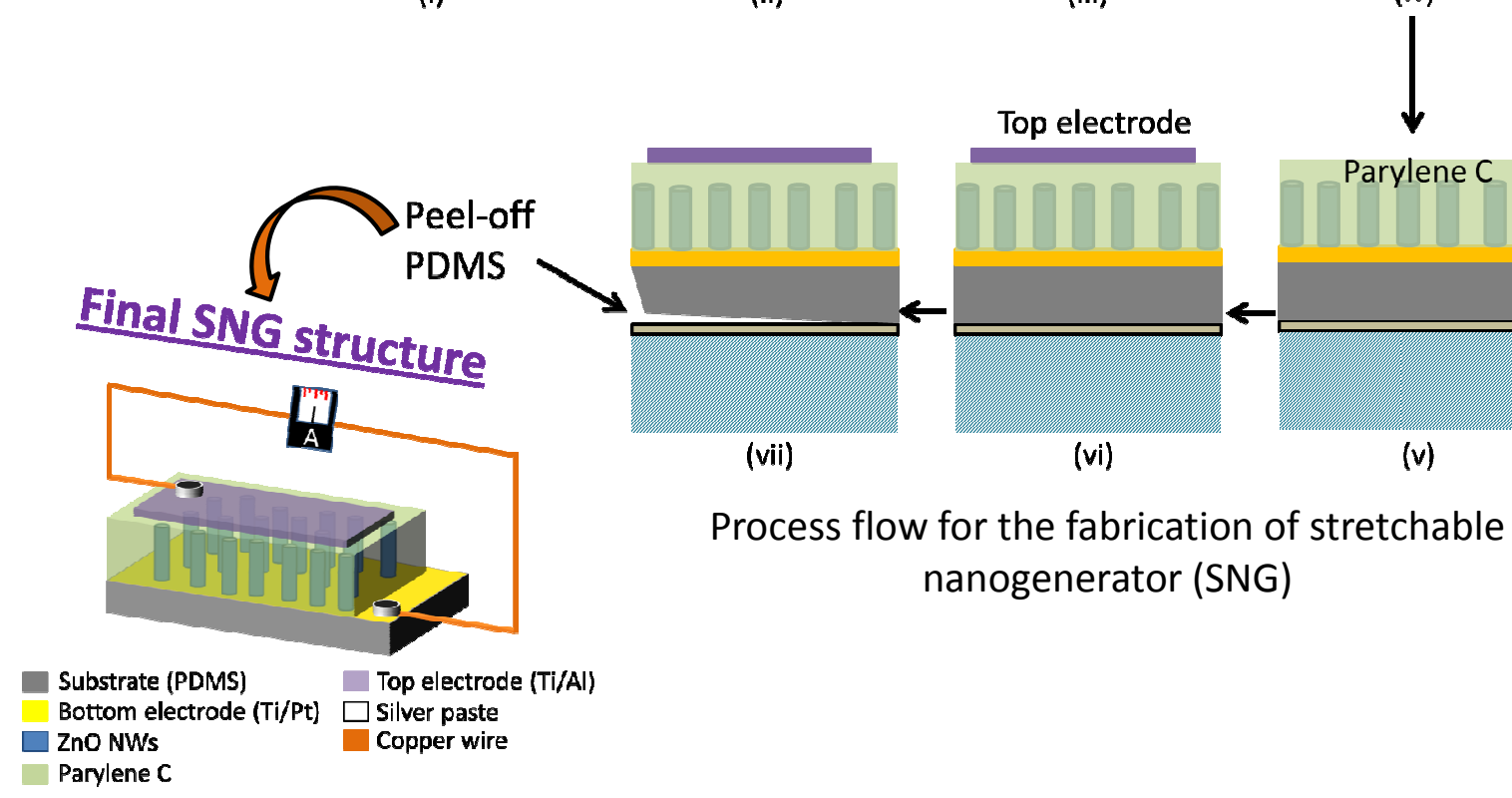

Figure 1. Schematic diagrams of the fabrication process for the organic/inorganic hybrid stretchable nanogenerator (SNG). 
(a)

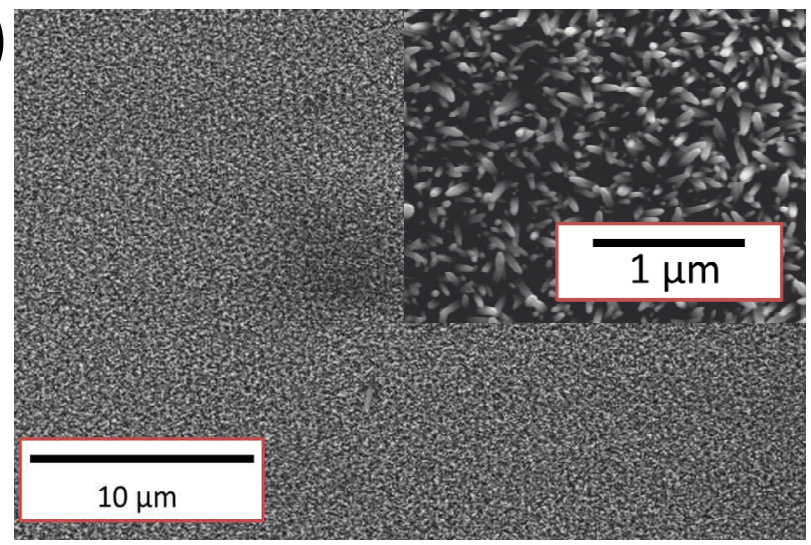

(c)

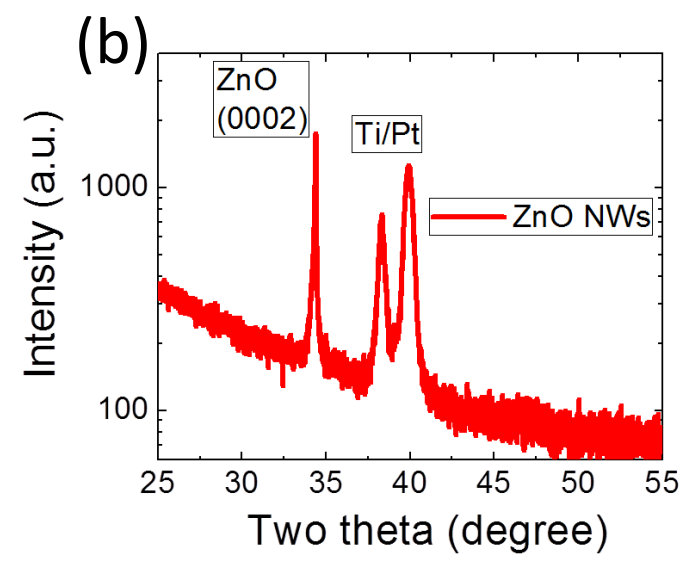

(d)

(e)
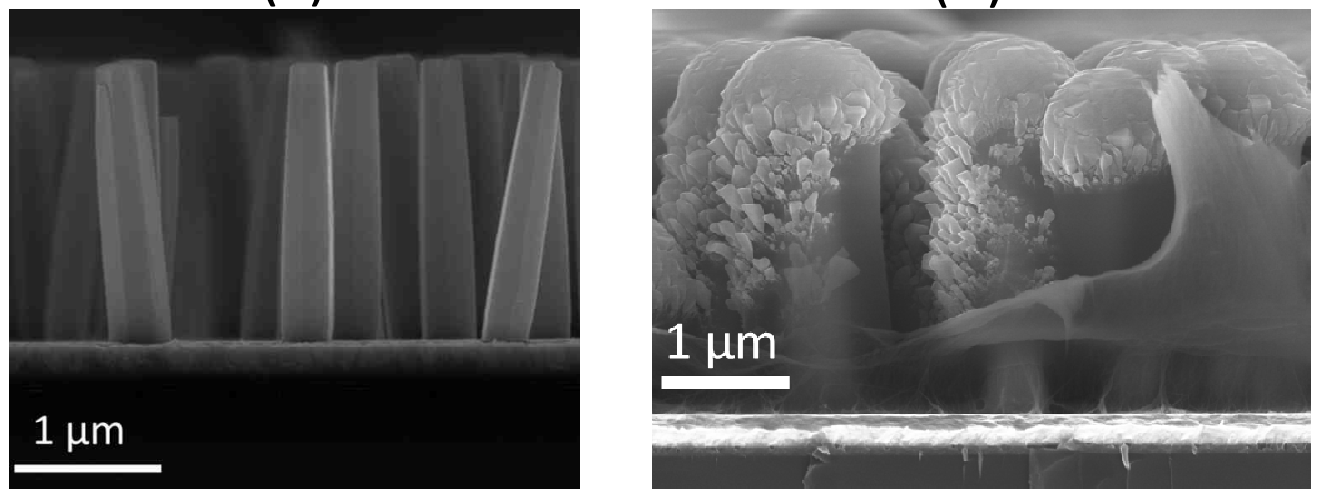

Top metal

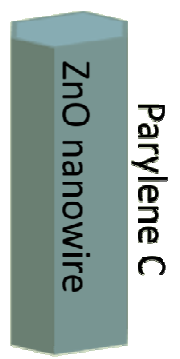

Figure 2. Morphological and structural characterization of as-grown vertically aligned $\mathrm{ZnO}$ NWs: (a) low magnification top-view SEM image of NWs grown on PDMS. The inset shows the high magnification SEM image. (b) XRD pattern. (c) SEM image of NWs grown on silicon (d) SEM image after parylene $\mathrm{C}$ and metal deposition on NWs grown on silicon. The image shows the high degree of parylene $\mathrm{C}$ infiltration between the NWs and its high conformity over the $\mathrm{ZnO} \mathrm{NWs}$ and (e) Schematic representation of $\mathrm{ZnO}$ NW-parylene composite. 


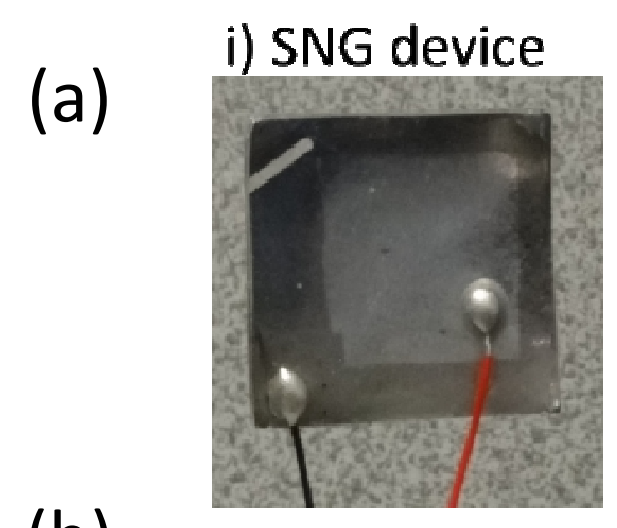

(b)

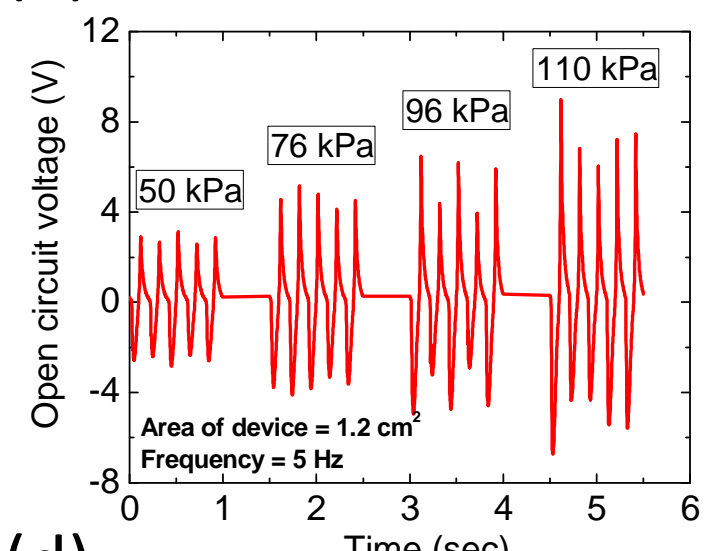

(d)

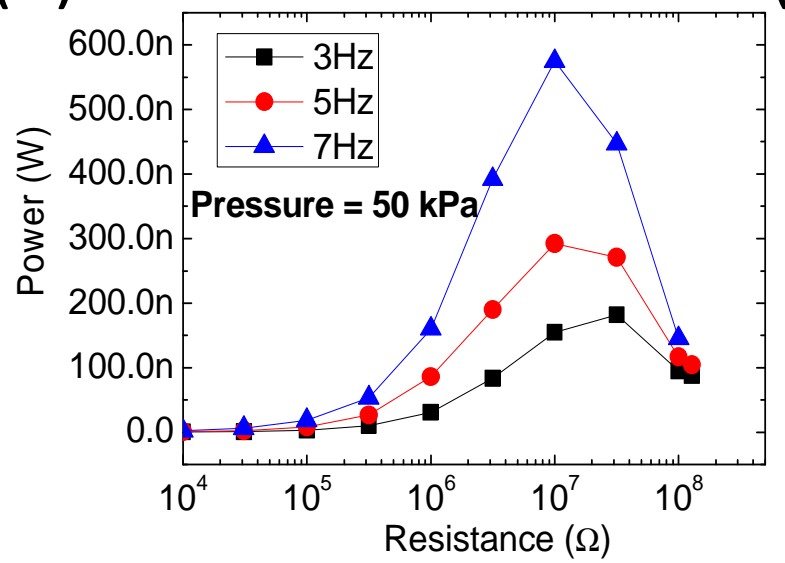

ii) Folded

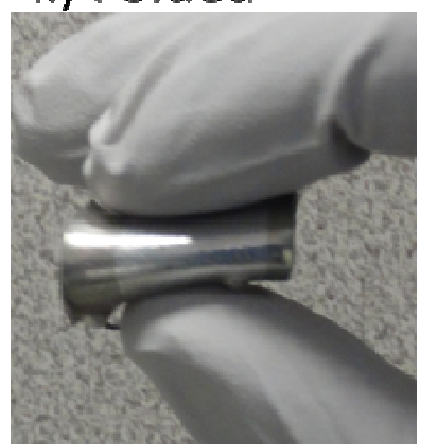

iii) Stretched

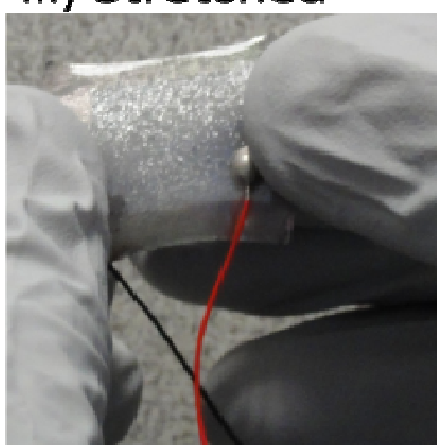

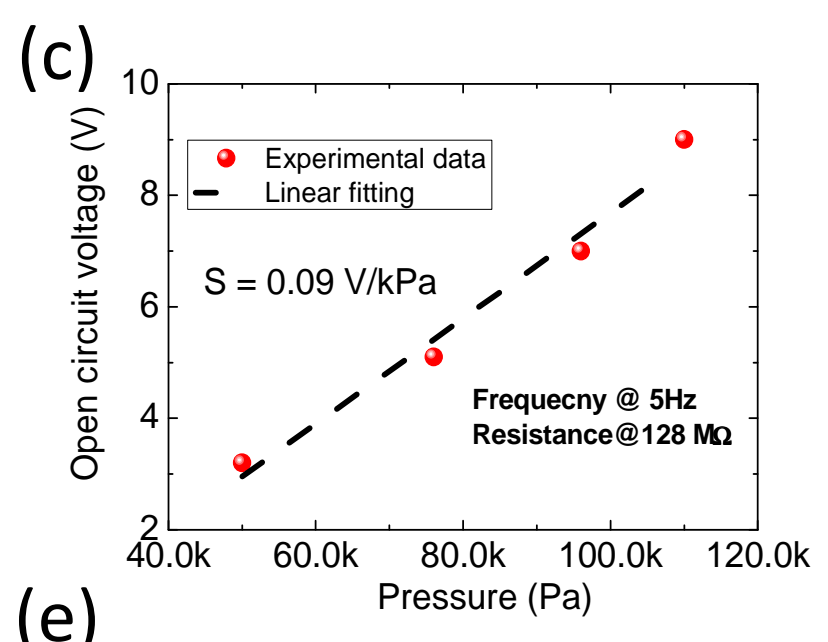

(e)

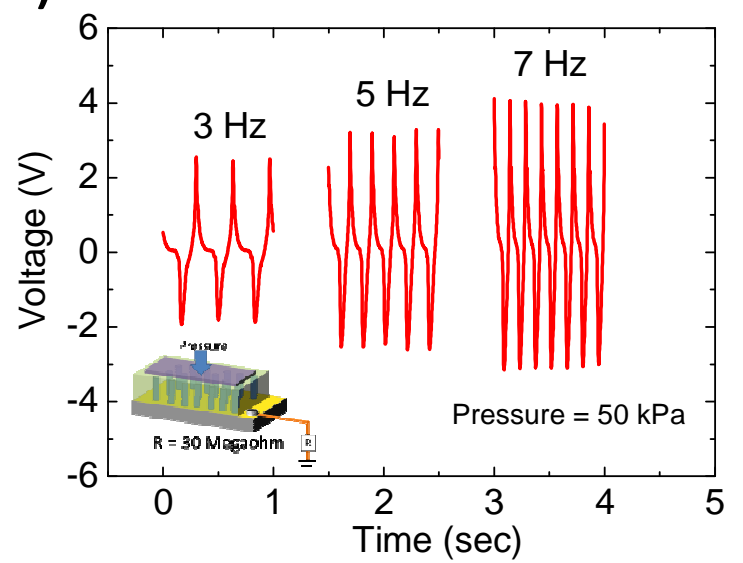

Figure 3. Functional characterization of the fabricated SNG devices: (a) an optical image. (b) Output open circuit voltage w.r.t. applied compressive pressure. (c) Summarized variation of peak voltage across $128 \mathrm{M} \Omega$ resistance at $5 \mathrm{~Hz}$ of frequency. (d) Peak output power as a function of load resistance at various frequencies. (e) Output open circuit voltage as a function of frequency at constant pressure of $50 \mathrm{kPa}$. 


\section{(a) No excitation}
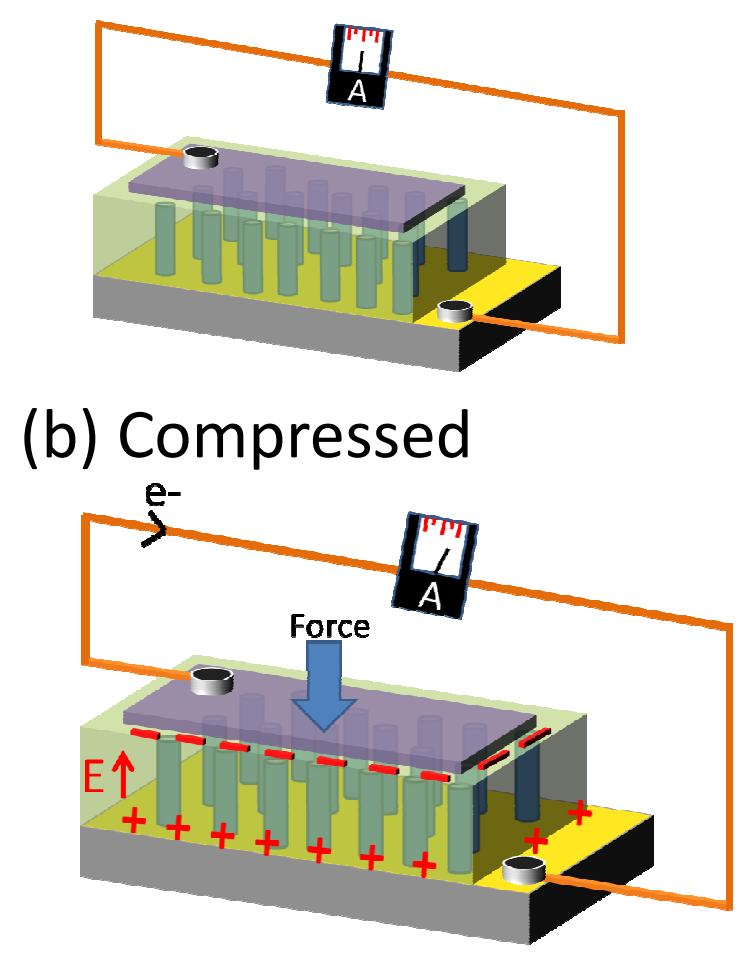

Substrate (PDMS)

Bottom electrode (Ti/Pt)

ZnO NWs

Parylene C

Top electrode (Ti/Al)

\section{(c) Relaxed}

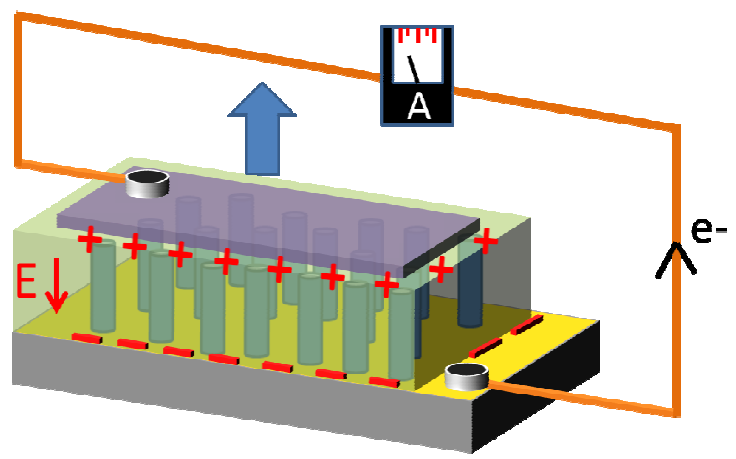

Figure 4. The working mechanism of the fabricated SNG devices: (a) No piezoelectric output voltage generated in the absence of any external mechanical strain. (b) The piezoelectric induced flow of the electrons from top to bottom electrode through the external load with the applied vertical compressive strain. (c) With the removal of the applied strain, the relaxation of the strained $\mathrm{ZnO}$ NWs changes the direction of the electron flow from the bottom to top electrode through the external load. 


\section{(a) SNG on Bank card}

Front side

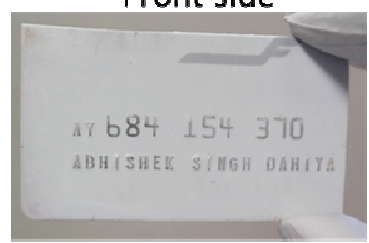

(b)
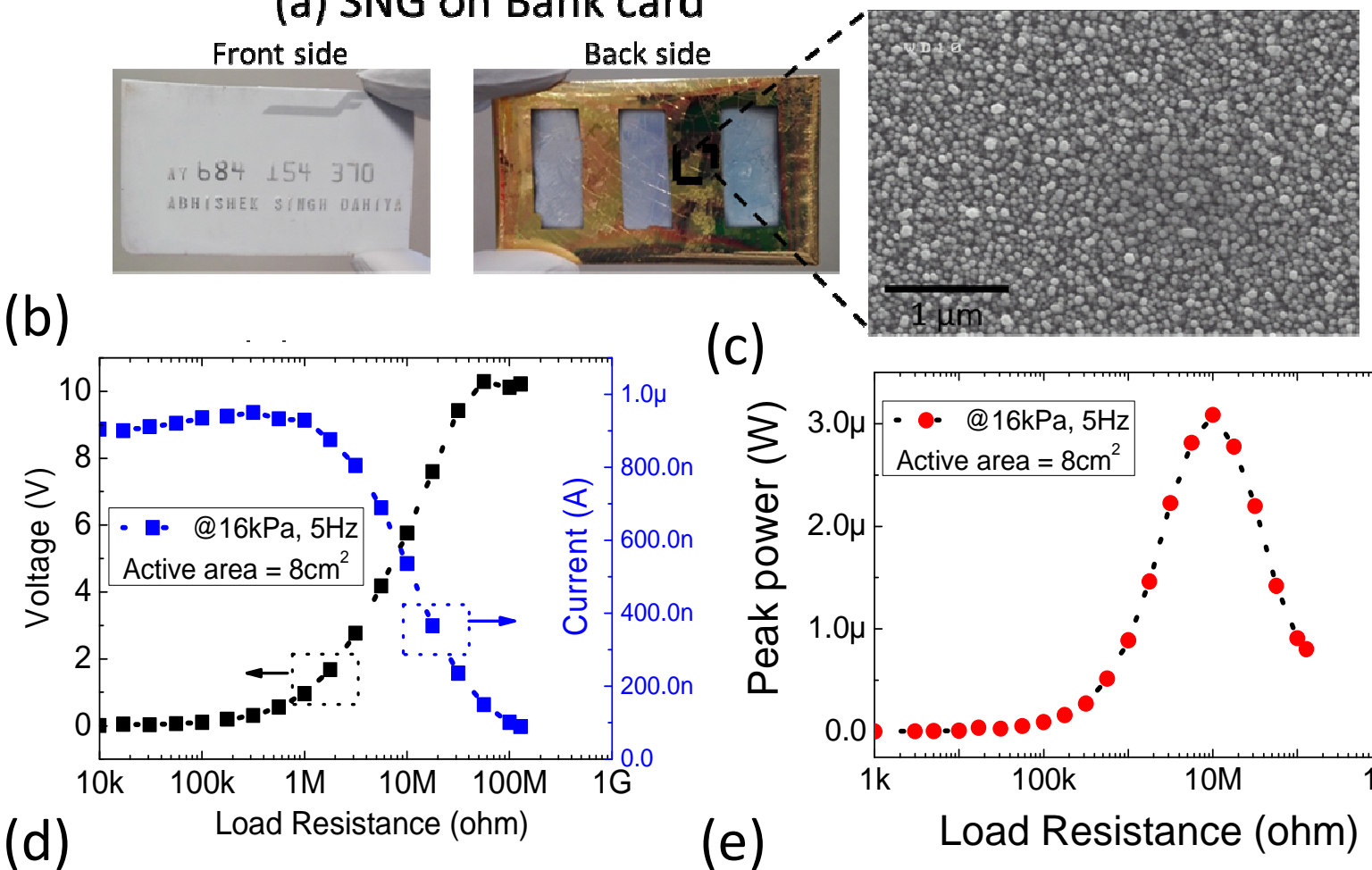

(c)
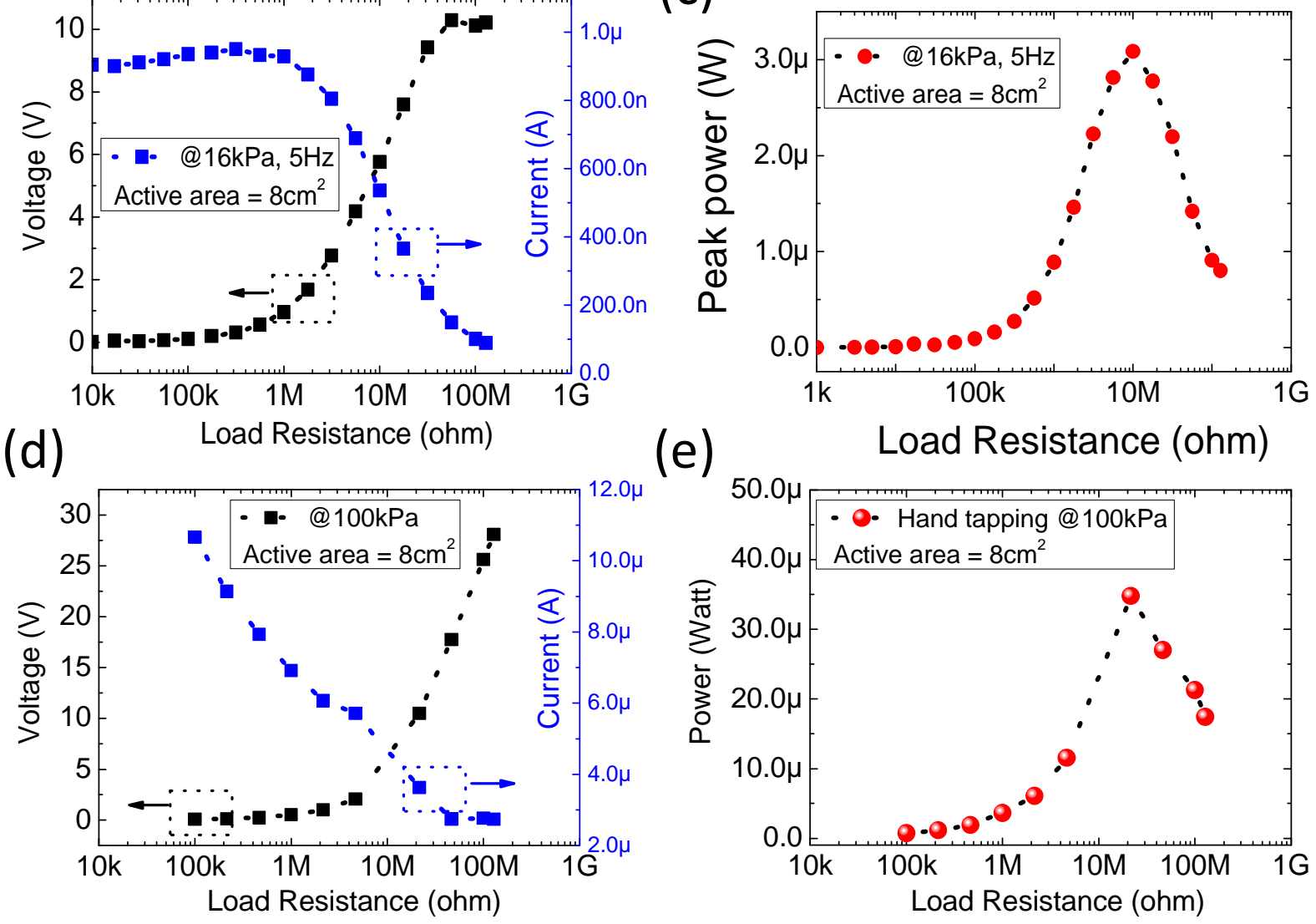

(e)

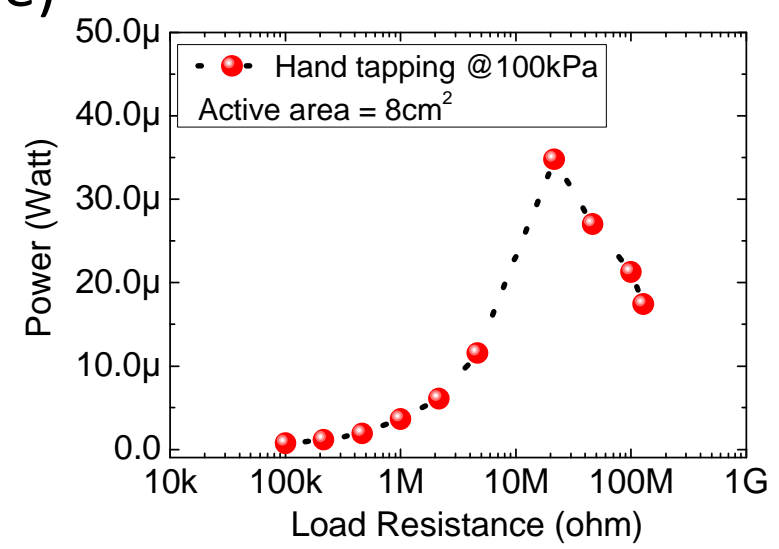

Figure 5. Electric output from large SNG device fabricated on typical bank cards: (a) optical image of the bank card and fabriacted device at the back side of it. SEM image showing the as-grown ZnO NWs. (b) Voltage and current amplitude as a function of load resistance at 16 $\mathrm{kPa}$ of applied compressive pressure. (c) Peak output power as a function of load resistance corresponding to the electrical results shown in figure panel c. (d) Voltage and current amplitude as a function of load resistance at $100 \mathrm{kPa}$ of applied compressive pressure. (e) Peak output power as a function of load resistance corresponding to the electrical results shown in figure panel $\mathrm{d}$. 

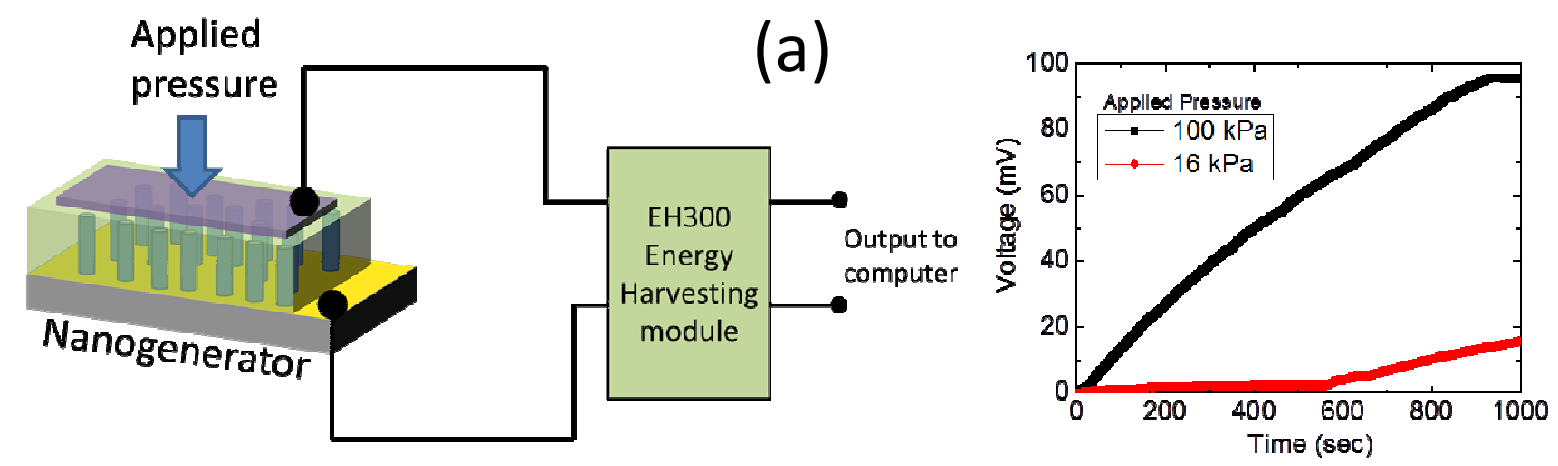

(b)

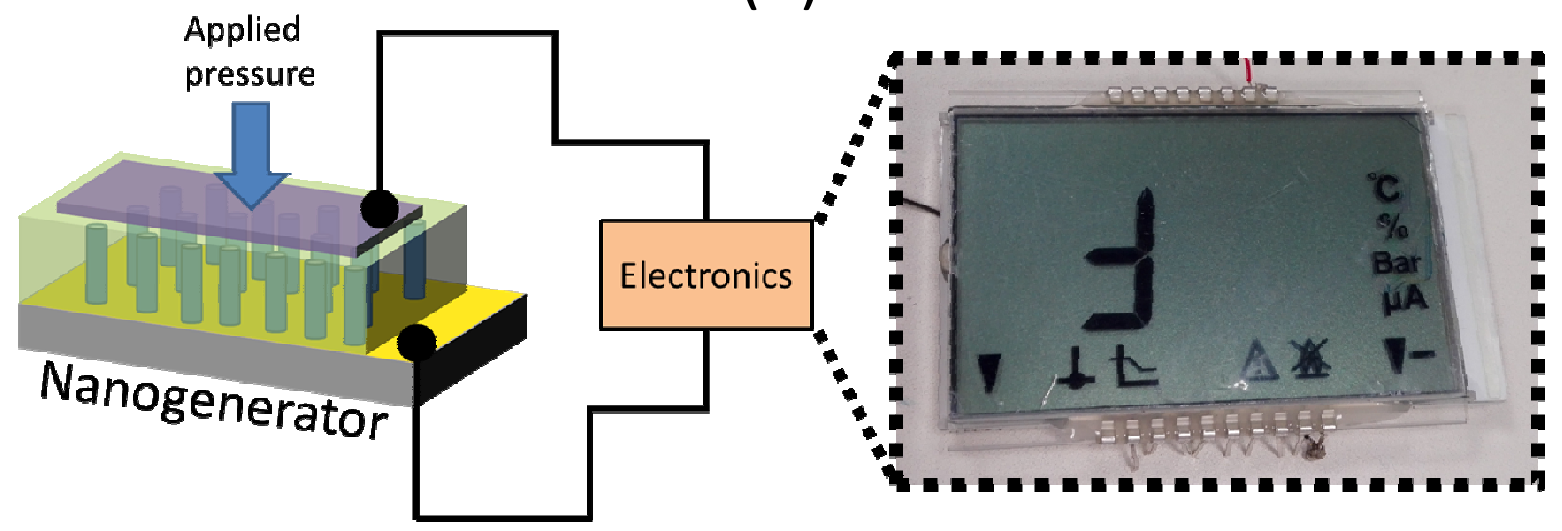

Figure 6. Demonstration of SNG device for energy harvesting. (a) Schematic of the circuit used for charging capacitor. The graph on the right displays the charging of $1 \mathrm{mF}$ capacitor for different applied compressive pressure. (b) Schematic of circuit for steady and continuous display of LCDs driven by SNG device. 


\section{a) Bending}

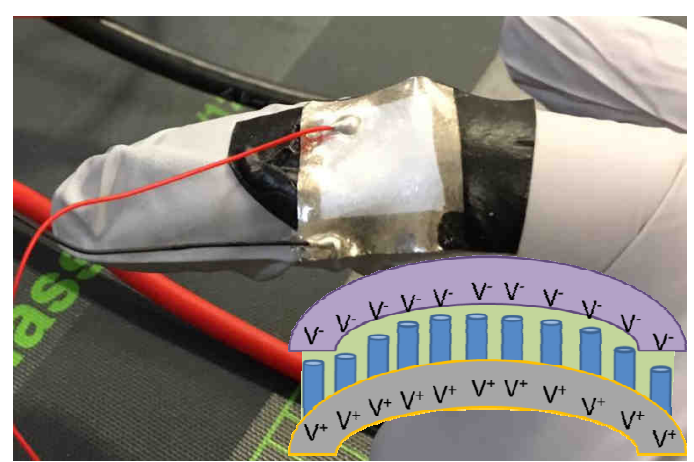

b) Releasing

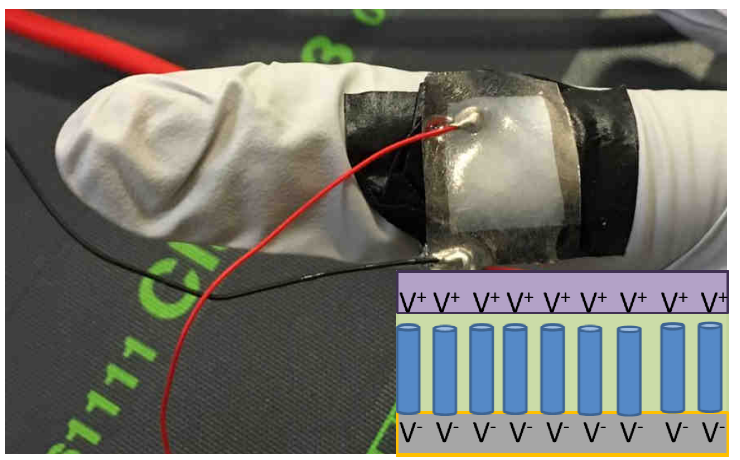

c)

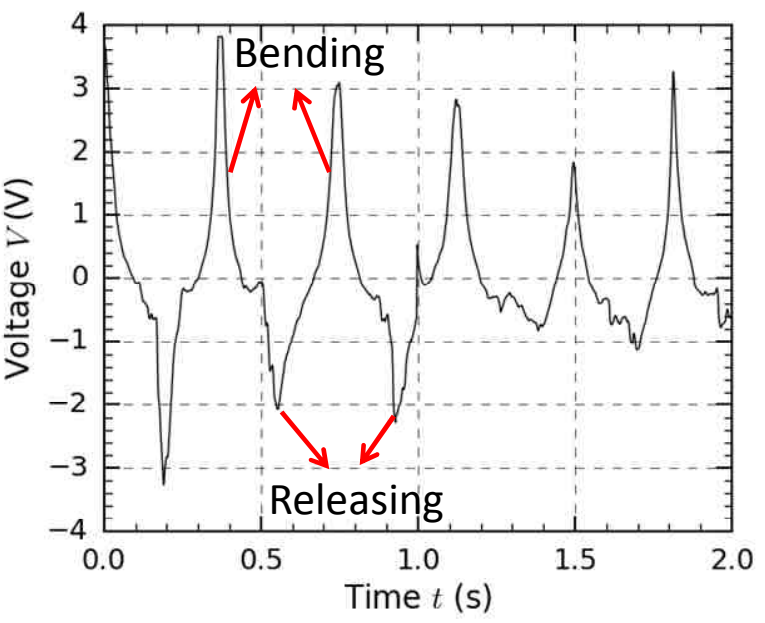

Figure 7. The wearability test of the stretchable SNG devices being fixed on the middle of an index finger: (a) Optical image of convex bending of the device. The inset schematically shows the type of charges appearing at top and bottom electrode during bending of the index finger. (b) Optical image shows straight index finger. The inset schematically shows the release of stress and change in sign of induced piezo charges. (c) The open circuit voltage w.r.t. time showing peaks in positive side during bending stage and in negative during releasing stage. 
Table 1. ZnO based PENG devices investigated in mechanical energy recovery and the corresponding output performances

\begin{tabular}{|c|c|c|c|c|c|c|c|c|}
\hline $\begin{array}{c}\text { NG } \\
\text { active } \\
\text { material }\end{array}$ & Metal & Substrate & $\begin{array}{c}\text { Divice } \\
\text { Dimensions } \\
{\left[\mathbf{c m}^{2}\right]}\end{array}$ & $\begin{array}{c}\text { Mechanical } \\
\text { loading: } \\
\text { Pressure } \\
{[\mathbf{M P a}]}\end{array}$ & $\begin{array}{c}\text { Mechanical } \\
\text { loading: } \\
\text { Force } \\
{[\mathbf{N}]}\end{array}$ & $\begin{array}{c}\text { Open } \\
\text { circuit } \\
\text { voltage } \\
\mathbf{( V )}\end{array}$ & $\begin{array}{c}\text { Short } \\
\text { circuit } \\
\text { current } \\
{[\boldsymbol{\mu A}]}\end{array}$ & Ref. \\
\hline $\begin{array}{c}\mathrm{ZnO} \\
\mathrm{NWs}\end{array}$ & $\mathrm{Al}$ & Silicon & N/A & N/A & 1.5 & 0.06 & - & {$[49]$} \\
\hline $\begin{array}{c}\mathrm{ZnO} \\
\mathrm{NWs}\end{array}$ & $\mathrm{Cr} / \mathrm{Au}$ & Polyester & 1 & N/A & N/A & 5 & 0.3 & {$[50]$} \\
\hline $\mathrm{ZnO}$ film & $\mathrm{AZO}$ & Ecoflex & 0.25 & $\begin{array}{c}\text { Compressive } \\
\text { strain: } 0.22 \%\end{array}$ & N/A & 1 & $1 \times 10^{-4}$ & {$[51]$} \\
\hline $\begin{array}{c}\mathrm{ZnO} \\
\mathrm{NWs}\end{array}$ & $\begin{array}{c}\mathrm{ITO} \\
\text { and } \\
\mathrm{Al}\end{array}$ & Silicon & 1 & 1 & 100 & 37 & 12 & {$[25]$} \\
\hline $\begin{array}{l}\mathrm{ZnO} \\
\mathrm{NWs}\end{array}$ & $\begin{array}{c}\mathrm{Au} \\
\text { and } \\
\mathrm{Al}\end{array}$ & PDMS & 1.2 & 0.1 & 13 & 9 & 0.5 & $\begin{array}{c}\text { This } \\
\text { work }\end{array}$ \\
\hline
\end{tabular}

